\title{
CSF SOMATOSTATIN IN ALZHEIMER'S DISEASE AND MAJOR DEPRESSION: RELATIONSHIP TO HYPOTHALAMIC-PITUITARY-ADRENAL AXIS AND CLINICAL MEASURES
}

\author{
Susan E. Molchan, ${ }^{1}$ James L. Hill, ${ }^{2}$ Rick A. Martinez, ${ }^{1}$ \\ Brian A. Lawlor, ${ }^{3}$ Alan M. Mellow, ${ }^{4}$ David R. Rubinow, \\ Garth Bissette, ${ }^{6}$ Charles B. Nemeroff,${ }^{7}$ and Trey Sunderland ${ }^{1}$ \\ 'Section on Geriatric Psychopharmacology, ${ }^{2}$ Unit on Biostatistics, Laboratory of Clinical \\ Science, ${ }^{5}$ Section on Behavioral Endocrinology, Biological Psychiatry Branch, National \\ Institute of Mental Health, Bethesda, Maryland, U.S.A. ${ }^{3}$ Department of Psychiatry, University \\ of Dublin, Dublin, Ireland ${ }^{4}$ Department of Psychiatry, University of Michigan, Ann Arbor, \\ Michigan, U.S.A. ${ }^{6}$ Department of Psychiatry, Duke University, Durham, North Carolina, \\ U.S.A. 'Department of Psychiatry and Behavioral Sciences, Emory University School of \\ Medicine, Atlanta, Georgia, U.S.A.
}

(Received 1 October 1992; in final form 22 April 1993)

\begin{abstract}
SUMMARY
Patients with Alzheimer's disease (AD) and major depression have been shown to have overlapping clinical symptoms and biological markers, including decreased concentrations of cerebrospinal fluid (CSF) somatostatin-like immunoreactivity (SLI), which may be related to alterations in the hypothalamic-pituitary-adrenal axis activity. As in prior studies, we found that CSF SLI was significantly decreased in a group of AD patients $(N=49)$ and a group of elderly patients with major depression $(N=18)$, as compared with 13 age-matched controls $(F[2,77]=12.9, p<.001)$. In the present study, CSF SLI and CSF corticotropin-releasing factor correlated significantly within the group of AD patients $(r=0.49, p<.0004)$ and almost attained significance in the depressed patients $(r=0.47, p<.07)$. CSF SLI correlated significantly with urinary free cortisol within each patient group $(r=-0.51, p<.03)$. Clinical measures of dementia severity and depression did not consistently correlate with CSF SLI in either patient group.
\end{abstract}

\section{INTRODUCTION}

DEPRESSED MOOD HAS been increasingly recognized as an important symptom in Alzheimer's disease (AD) patients; from $17 \%$ to $87 \%$ are estimated to have significant depression at some time during the course of the disease (Fischer et al., 1990; Lazarus et al., 1987; Rovner et al., 1989). Biological markers of major depression such as nonsuppression on the dexamethasone suppression test (DST) and blunting of the thyroid-stimulating hor-

Address correspondence and reprint requests to: Dr. Susan Molchan, NIH Clinical Center, 10/ 3D41, 9000 Rockville Pike, Bethesda, MD 20892. 
mone response to administered thyrotropin-releasing hormone may also occur in $\mathrm{AD}$ patients to about the same degree as in patients with major depression (Carroll, 1985; Greenwald et al., 1986; Loosen, 1985; Molchan et al., 1990, 1991b; Raskind et al., 1982; Skare et al., 1990). In addition, patients with AD and major depression have been consistently shown to have decreased concentrations of cerebrospinal fluid (CSF) somatostatin-like immunoreactivity (SLI) (Agren \& Lundqvist, 1984; Beal et al., 1986; Bissette et al., 1986; Davis et al., 1988; Molchan et al., 1991a; Oram et al., 1981; Rubinow, 1986; Soininen et al., 1984; Sunderland et al., 1987). In the brain, the highest concentrations of somatostatin occur in the hypothalamus and limbic system (Rubinow, 1986), areas thought to be involved in cognitive and affective functions.

Interactions between somatostatin and the hypothalamic-pituitary-adrenal (HPA) axis have been examined in many preclinical and clinical studies (Doran et al., 1986; Kaye et al., 1988; Rubinow, 1986; Serby et al., 1986; Wolkowitz et al., 1987). Somatostatin has been shown to inhibit stimulated and stress-induced corticotropin-releasing factor (CRF) and corticotropin (ACTH) release (Brown et al., 1984; Heisler et al., 1982; Richardson \& Schronbrunn, 1981). A positive relationship has generally been found between CSF SLI and CSF CRF in normal control and some patient populations (Berrettini et al., 1987; Kaye et al., 1988; Rubinow et al., 1987). In patients with major depression (Rubinow, 1986) and dementia (Serby et al., 1986), CSF SLI has been shown to correlate inversely with postdexamethasone plasma cortisol concentrations.

In this study, we sought to determine if there are similarities in relationships between CSF SLI, HPA measures, and measures of mood in AD patients and in patients with major depression because of the overlapping clinical symptoms and abnormal biological measures, including reduced CSF SLI levels, in these two illnesses.

\section{METHODS}

\section{Subjects}

Forty-nine patients with $\mathrm{AD}$ (mean age $\pm \mathrm{SD}=66.3 \pm 8.6$ years; 23 women, 26 men) and 18 patients with major depression $(64.6 \pm 9.9$ years; 12 women, 6 men) were included in the study. Thirteen normal controls $(63.5 \pm 10.0$ years; 3 women, 10 men) were included for comparisons of CSF SLI and CRF. All patients were studied as inpatients at the National Institute of Mental Health (NIMH); normal controls were studied as outpatients. Primary degenerative dementia of the Alzheimer type (AD) and major depression were diagnosed according to DSM-III-R criteria (American Psychiatric Association, 1987) using semi-structured interviews, laboratory and brain imaging studies, and physical examinations. Clinical and demographic data for the patients are summarized in Table I. Some AD patients had significant depressive symptoms, and may have had a prior history of major depression. Patients with serious medical problems were excluded from the study. Those patients diagnosed with major depression had a prior history of depressive episodes (i.e., their depression was not late-onset), did not have significant cognitive impairment at the time of testing, and responded to treatment with either antidepressant medication or electroconvulsive therapy. Clinical and biological data were collected during a 3-week drug-free period. Patients diagnosed with major depression and normal controls were administered the Wechsler Memory Scale-Revised (Wechsler, 1987 ) to ensure that their cognitive functioning was within the range of normal. Controls were also screened using a semi-structured interview, physical examination, and laboratory tests; those with a personal or family history of any significant medical, cognitive, 


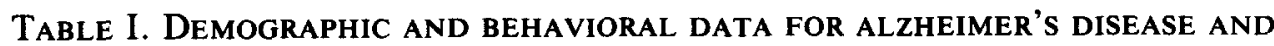
MAJOR DEPRESSSION PATIENTS (MEAN \pm SD)

\begin{tabular}{lcc}
\hline & Alzheimer's $(\boldsymbol{n}=\mathbf{4 9 )}$ & Depressed $(\boldsymbol{n}=\mathbf{1 8})$ \\
\hline Age (years) & $66.3 \pm 8.6$ & $64.6 \pm 9.9$ \\
Gender & $23 \mathrm{~F}, 26 \mathrm{M}$ & $12 \mathrm{~F}, 6 \mathrm{M}$ \\
Illness duration (years) & $4.2 \pm 2.6$ & - \\
Age of onset (years) & $62.1 \pm 8.9$ & - \\
Dementia Mood Assessment Scale-17 & $22.9 \pm 10.1$ & - \\
Hamilton Depression Scale (17 item) & - & $6.9 \pm 7.1$ \\
Bunney-Hamburg Global Rating Scales & $4.0 \pm 1.8$ & $6.6 \pm 1.4$ \\
$\quad$ Depression & $4.7 \pm 1.6$ & $2.1 \pm 2.2$ \\
$\quad$ Anxiety & $1.8 \pm 1.3$ & - \\
Psychosis & $4.5 \pm 0.9$ & - \\
Dementia severity & $1.6 \pm 0.6$ & \\
$\quad$ Global Deterioration Scale & & \\
\hline
\end{tabular}

or psychiatric disorder were excluded. They were recruited from the community and paid for their participation. All subjects were free of centrally active drugs for at least 3 weeks before the study. The study was approved by the NIMH protocol review committee after review of scientific and ethical considerations. All subjects gave written informed consent and for $\mathrm{AD}$ patients, a relative also signed the consent form.

\section{Rating Scales}

Dementia severity was rated by trained members of the clinical research team using the Global Deterioration Scale (Reisberg et al., 1982) and the Clinical Dementia Rating Scale (Hughes et al., 1982). They were also evaluated with the Dementia Mood Assessment Scale (DMAS) (Sunderland et al., 1988a, 1988b), a 24-item scale in which the first 17 items were designed to measure mood in dementia (DMAS-17) and the last 7 items to measure cognitive and functional impairment. We also used the modified BunneyHamburg Global Behavioral Rating Scales (Bunney \& Hamburg, 1963; Sunderland et al., 1988a) to rate aspects of behavior and mood, with scores ranging from 0 (no impairment) to 13-15 (very severe). High inter-rater reliability had been established previously for both the DMAS-17 and the Global Rating Scales in a group of AD patients (Sunderland et al., 1988a). To rate depression severity in patients diagnosed with major depression, we used the Hamilton Depression Scale (Hamilton, 1960) as well as the Bunney-Hamburg Global Behavioral Rating Scales.

\section{CSF Measures}

After an overnight fast, lumbar punctures were performed between $0800 \mathrm{~h}$ and $0900 \mathrm{~h}$ on subjects in the lateral decubitus position. Subjects were on bed-rest prior to the lumbar puncture, except for voiding. The lumbar puncture was usually the last test done during a patients's hospitalization, and care was taken to leave enough days between it and other tests that were done. The 26th milliliter of collected CSF was immediately frozen without preservatives on dry ice and then stored at $-70^{\circ} \mathrm{C}$ for later measurement of SLI. The SLI radioimmunoassay (RIA) used ${ }^{125} \mathrm{I}$-tyrosine-1-somatostatin, rabbit antisomato- 
statin antiserum (INC-STAR Corp., Stillwater, MN), synthetic cyclic somatostatin standards, and charcoal separation, and was performed using procedures described elsewhere (Patel et al., 1977). Assay sensitivity is $1 \mathrm{pg} /$ tube, with an $E D_{50}$ of $8.6 \mathrm{pg} / \mathrm{tube}$. The antisomatostatin antibody used is directed toward the midportion of the tetradecapeptide, so it recognizes $N$-terminal extensions of SRIF-14, such as SRIF-28. SLI for all subjects was measured in one of two large assays, and samples from $A D$, depressed, and normal subjects were run in the same assays. All samples were measured in duplicate. The intraassay coefficient of variation was about $6 \%$; the interassay coefficient of variation for this assay is $12-15 \%$.

The CSF CRF RIA has been described in detail (Banki et al., 1987; Nemeroff et al., 1984) and included an ovine CRF antiserum provided by Dr. Wylie Vale (Salk Institute, La Jolla, CA). The assay has a sensitivity of $2.5 \mathrm{pg} /$ tube $(6.25 \mathrm{pg} / \mathrm{ml})$, an $\mathrm{IC}_{50}$ of $40 \mathrm{pg}$, and recognizes the CRF molecule in the 33-41 amino acid region. All samples were measured in a single assay with an intraassay variation of $7.9 \%$.

\section{Plasma and Urinary Free Cortisol}

Fourteen of the $\mathrm{AD}$ and 10 of the depressed patients received a DST, in which $1 \mathrm{mg}$ of dexamethasone was ingested at $2300 \mathrm{~h}$ and blood for cortisol measurement was collected at $0800 \mathrm{~h}$ and $1600 \mathrm{~h}$ the following day, after which they were stored at $-70^{\circ} \mathrm{C}$. Duplicate samples of serum cortisol were measured using RIA by Hazelton Laboratories, Rockville, MD. Within- and between-assay variations were $5.8 \%$ and $9.7 \%$, respectively. Subjects were considered nonsuppressors if either the $0800 \mathrm{~h}$ or the $1600 \mathrm{~h}$ postdexamethasone cortisol was $>5 \mathrm{mg} / \mathrm{dl}$.

The 24-hour urine collections were done by both patient groups under close supervision by nursing staff; aliquots were stored at $-70^{\circ} \mathrm{C}$. Urinary free cortisol (UFC) was measured using RIA by Hazleton Laboratories. Assay sensitivity is $0.2 \mathrm{mg} / \mathrm{dl}$, with negligible crossreactivity to other naturally occurring steroids, and coefficient of variation was $4.6 \%$.

\section{Data Analysis}

Age, CSF SLI, and HPA axis measures were compared between diagnostic groups by one-way ANOVA and post hoc Bonferroni $t$-tests (two-tailed). Pearson's productmoment correlations $(r)$ were used to explore relationships between CSF SLI, HPA measures, age, duration of illness, dementia severity, and mood. Comparison of CSF SLI with respect to gender and age of onset $(>65$ and $\&$ e $<65$ ) was made using Student's $t$-test (two-tailed). A Fisher's exact test was used to determine any difference between rates of DST nonsuppression between patient groups. Data are presented as the mean \pm SD.

\section{RESULTS}

\section{CSF SLI and Demographic and Clinical Variables}

CSF SLI concentrations and DST results for the depressed patients and controls and for 34 of the AD patients had been reported previously (Molchan et al., 1990, 1991a). Those data are included here as background for the examination of relationships with the HPA axis and clinical measures. Means for demographic and clinical variables for the patient groups are summarized in Table I. As reported previously (Bissette et al., 1986; Davis et al., 1988; Molchan et al., 1991; Sunderland et al., 1987), the CSF SLI concentration of age-matched controls $(62.4 \pm 13.3 \mathrm{pg} / \mathrm{ml})$ was significantly higher than 
TABLE II. BIOLOGICAL DATA FOR ALZHEIMER'S AND MAJOR DEPRESSION PATIENTS

\begin{tabular}{lcc}
\multicolumn{1}{c}{ Measure (mean \pm SD) } & Alzheimer's & Depression \\
\hline CSF SLI $(\mathrm{pg} / \mathrm{ml})^{*}$ & $36.9 \pm 15.2(49)$ & $45.1 \pm 15.5(18)$ \\
CSF CRH $(\mathrm{pg} / \mathrm{ml})^{*}$ & $76.7 \pm 26.1(49)$ & $78.6 \pm 24.6(18)$ \\
Baseline cortisol $(\mu \mathrm{g} / \mathrm{dl})$ & $15.9 \pm 6.6(13)$ & $20.1 \pm 12.6(9)$ \\
Post-dexamethasone plasma cortisol $(\mu \mathrm{g} / \mathrm{dl})$ & $1.5 \pm 0.7(14)$ & $7.6 \pm 10.5(10)^{* *}$ \\
$\quad$ 0800h & $3.1 \pm 2.9(14)$ & $6.8 \pm 8.0(9)$ \\
$\quad$ 1600h & $21.4(3)$ & $60.0(6)^{\dagger}$ \\
\% subjects with post-dex cortisol $>5 \mu \mathrm{g} / \mathrm{dl}$ & $61.2 \pm 31.3(23)$ & $92.3 \pm 62.6(16) \dagger$ \\
Urinary free cortisol $(\mu \mathrm{g} / 24 \mathrm{~h})$ & &
\end{tabular}

Number of subjects is given in parentheses.

*For normal controls CSF SLI $=62.4 \pm 13.3 \mathrm{pg} / \mathrm{ml}(n=13)$ and CRF $=87.1 \pm 15.8 \mathrm{pg} / \mathrm{ml}(n=11)$.

${ }^{* *} p<.05, \dagger p<.09$ difference between groups.

that of both patient groups $(F[2,77]=12.9, p<.001)$, and the levels between the AD and depressed patients did not differ significantly from each other (Table II). In the present study, age did not correlate with CSF SLI in either patient group, though it did within the group of 13 normal controls $(r=0.61, p<.03)$. No difference in CSF SLI concentration was found between genders within any of the subject groups, though the small sample size and inclusion of only three women in the normal control group increases the possibility of a false negative conclusion.

There were no significant correlations between CSF SLI and measures of dementia severity; $r=-0.06, p<.68, n=49$ for the Clinical Dementia Rating, and $r=-0.02$, $p<.89, n=49$ for the Global Deterioration Scale, nor was there a significant correlation between duration of dementia symptoms and SLI $(r=-0.13, p<.37, n=49)$. CSF SLI was not significantly different between AD patients with presenile-onset (age $<65$ ) $(35.3 \pm 15.1 \mathrm{pg} / \mathrm{ml}, N=26)$ and senile-onset $(39.3 \pm 16.0 \mathrm{pg} / \mathrm{ml}, N=23)$ of illness.

\section{SLI and Mood Measures}

Within the AD group, CSF SLI correlated with the degree of depression as measured by the DMAS (17 item) $(r=-0.40, n=49, p<.005)$, but not with the Global Depression Score $(r=-0.17, n=49, p<.23)$. Of the other Global Scale measures, only psychosis correlated significantly with CSF SLI $(r=-0.33, n=49, p<.02)$.

Within the group of patients with major depression, the Hamilton Depression Scale (both 17-item and total) score did not correlate significantly with CSF SLI $(r=-0.41$, $N=18, p<.09$, and $r=-0.36, N=18, p<.15$, respectively); nor did the Global Scale scores correlate significantly with CSF SLI concentration.

\section{HPA Axis Measures}

CSF CRF concentrations were not significantly different among subjects groups $(F[2$, 77] $=0.80 ; p<.46$ ) (Table II) (CSF CRF $=87.1 \pm 15.8 \mathrm{pg} / \mathrm{ml}, n=11$ normal controls). Normal controls did not participate in the DST or urine collections; the mean measures for the patient groups for these tests are summarized in Table II. The depressed patients had higher postdexamethasone cortisol concentrations than the AD patients, significantly for the $0800 \mathrm{~h}$ measure. The rate of DST nonsuppression and mean UFC level also tended to be higher within the group of depressed as compared with the AD patients $(p<.09)$. 
Table III. Correlations between CSF SLI AND HPA

AXIS MEASURES

\begin{tabular}{lcr}
\hline \multicolumn{1}{c}{ Measure } & Alzheimer's & Depressed \\
\hline CSF CRH & $0.49(49)^{*}$ & $0.47(16) \ddagger$ \\
Max post-dex plasma cortisol & $0.23(14)$ & $0.22(10)$ \\
Urinary free cortisol & $-0.51(23)^{\dagger}$ & $-0.54(16) \dagger$ \\
\hline
\end{tabular}

The correlation coefficient $(r)$ and number of subjects is given for each correlation.

${ }^{*} p<.0004,{ }^{\dagger} p<.03, \neq p<.07$.

\section{SLI and HPA Axis Measures}

Table III summarizes correlations between CSF SLI and HPA axis measures for the patient groups. CSF CRF and SLI concentrations correlated positively within each group, significantly in the AD group and at a trend level in the depressed patients. Within the group of normal controls, CSF SLI and CRF did not correlate $(r=0.08, p<.84)$. Postdexamethasone plasma cortisol levels did not correlate with SLI in either patient group, and UFC correlated negatively with SLI in both groups (Table III). There was no significant difference in CSF SLI between DST suppressors and nonsuppressors in either the $\mathrm{AD}(t=0.89, d f=12, p<.39)$ or the depressed group $(t=0.31, d f=8, p$ $<.77$ ). Of the HPA measures, only CRF and UFC correlated significantly within the AD group $(r=-0.43, p<.05)$, although not in the group with major depression $(r=$ $0.1, p<.71)$.

\section{DISCUSSION}

As reported previously, CSF SLI was significantly decreased in the patients with AD and major depression as compared with normal controls (Agren \& Lundqvist, 1984; Beal et al., 1986; Davis et al., 1988; Molchan et al., 1991a; Oram et al., 1981; Rubinow, 1986; Soininen et al., 1984; Sunderland et al., 1987). Not previously reported for this patient sample, and consistent with most (McDonald \& Nemeroff, 1991; Nemeroff et al., 1984; Pomara et al., 1989) but not all prior studies (May et al., 1987; Mouradian et al., 1986; Suemaru et al., 1991), mean CSF CRF did not differ significantly between AD patients and controls.

In patients with major depression too, no significant difference was found in CRF when compared with normals. This is different from the increased CRF concentrations reported in most studies of depressed patients (Nemeroff, 1992; Nemeroff et al., 1984). Those prior studies included younger patients, and age has been shown to be related to other HPA axis abnormalities, such as hypercortisolemia and DST nonsuppression, in patient groups (Greden et al., 1986; Sapolsky et al., 1987). Conceivably, the negative feedback of this hypercortisolemia could act to lower CRF concentrations, which may otherwise have been elevated, as in younger depressed patients. Many of the older patients included in our study too, were probably more chronically depressed than younger patients included in prior studies. Older patients often have more persistent symptoms and may be less likely to recover fully (Blazer, 1989). Such chronic depression may lead to greater adrenal gland hypertrophy over time, and increased rates and levels 
of hypercortisolemia (Amsterdam et al., 1987; Nemeroff et al., 1992). To test this hypothesis more completely, larger numbers of older subjects need to be studied.

It should also be noted that the mean CRF concentration for our normal control group $(87.1 \mathrm{pg} / \mathrm{ml})$ was high compared to values for normals from prior studies $(40-60 \mathrm{pg} / \mathrm{ml})$ (Banki et al., 1987; France et al., 1988; Nemeroff et al., 1984). Prior studies included subjects of lower mean age than those included in our study, and although age has not been shown to correlate with CRF concentration (Banki et al., 1987; France et al., 1988), further studies should be done on its effects on CSF CRF and other HPA axis measures.

Relationships between SLI and CRF and UFC have not, to our knowledge, been examined in AD patients. Consistent with some prior studies in other patient groups, CSF SLI correlated positively with CSF CRF within each of our patient groups (Berrettini et al., 1987; Kaye et al., 1988; Rubinow et al., 1987), though in the depressed patients at a trend level of statistical significance. UFC correlated negatively with CSF SLI within each patient group (Table III), consistent with prior findings of inverse correlations between plasma cortisol and CSF SLI (Doran et al., 1986; Kaye et al., 1988; Rubinow, 1986), including in one study of dementia patients (Serby et al., 1986). Decreased SLI may be secondary to increased peripheral cortisol levels, in that SLI secretion has been shown to decrease after dexamethasone in vitro (Cote et al., 1986), and CSF SLI levels in humans have been shown to decrease after prednisone administration (Wolkowitz et al., 1987). Conversely, possibly with decreased SLI concentrations, and therefore a loss of inhibitory feedback (Brown et al., 1984; Heisler et al., 1982; Lamberts, 1988; Nicholson et al., 1984; Reisine, 1984; Richardson \& Schronbrunn, 1981) on CRF and ACTH in these pathological states, a hypercortisolemic state may ensue (Doran et al., 1986; Kaye et al., 1988; Rubinow, 1986; Wolkowitz et al., 1987). A suprapituitary source of neuroendocrine alterations has also been indicated by CRF stimulation test responses in patients with major depression (Gold et al., 1986; Holsboer et al., 1984; Lesch et al., 1988) and in one study of patients with AD (Lesch et al., 1990), in that ACTH responses have been shown to be blunted as compared to controls, with normal cortisol responses.

Another indication that the neuroendocrine abnormalities in $\mathrm{AD}$ may arise from a central source is that hypothalamic neuropathology has been documented in the illness (Hirano \& Zimmerman, 1962; Ishii, 1966; Saper \& German, 1987; Sparks et al., 1988). As noted above, decreased hypothalamic somatostatin may allow a disinhibition of the HPA axis (Rubinow, 1986). Alternatively, the somatostatinergic and HPA systems may be disrupted because of pathology that affects each of them separately, or the HPA axis may become disinhibited by an indirect effect of somatostatin via, for example, catecholamines, which regulate the HPA axis (Brown et al., 1984; Doran et al., 1986; Garcia-Sevilla et al., 1978; Gothert, 1980). Loss of glucocorticoid receptors from another central site of pathology in AD, the hippocampus (Coyle et al., 1983; Katzman, 1986), and subsequent feedback insensitivity, has also been hypothesized to lead to glucocorticoid hypersecretion (Sapolsky et al., 1987).

The negative correlations between UFC and CRF within the group of AD patients may be an indication of a relatively intact feedback mechanism onto CRF, hence CRF concentrations were not shown to be elevated as compared with normal controls. There was no correlation between CRF and UFC in the depressed patients, possibly because the mechanisms of the HPA aberrations in depression differ from that in AD patients. Some studies have indicated that a deficient glucocorticoid feedback response may contribute to the HPA abnormalities in depression (Axelrod \& Reisine, 1984; Lesch et al., 1988; Lowy et al., 1988; Maes et al., 1990). 
Twenty-four hour collections of UFC have been used as an estimate of circulating unbound cortisol secretion (Beisel et al., 1964; Carroll \& Mendels, 1976; Eddy et al., 1973; Lindholm, 1973). The depressed patients in our study had higher UFC levels than the $\mathrm{AD}$ patients, consistent with the higher mean postdexamethasone plasma cortisol concentration in that group and the trend towards a larger number of nonsuppressors. Elevated UFC has been reported in patients with major depression in some (Berger et al., 1982; Rubin et al., 1987; Stokes et al., 1984) but not all (Vandewalle et al., 1983) studies, and in one study of dementia patients (Maeda et al., 1991).

In AD patients, some (Soininen et al., 1984; Tamminga et al., 1987) but not all studies (Beal et al., 1986; Davis et al., 1988; Sunderland et al., 1987) have found significant correlations between decreased levels of SLI and dementia severity. Only one previous study examined the relationship between SLI level and depression in AD patients and as in the present study, no consistent relationship was found (Sunderland et al., 1987). Similarly, most though not all (Agren \& Lundqvist, 1984) studies of depressed patients have not shown a correlation between measures of depressed mood and CSF SLI (Rubinow, 1986; Sunderland et al., 1987).

Neuroendocrine systems have many overlapping regulatory mechanisms, so it is difficult to determine the role of any one substance in the biological abnormalities discussed. The positive correlations between CSF SLI and CRF and negative correlations between SLI and a peripheral HPA axis measure, UFC, found in the patients in the present and prior studies, are indicative of some of these interrelationships. Further studies of clinical measures, neuropeptides, and hormones in $\mathrm{AD}$ and major depression may encourage the development of novel therapeutic approaches and help elucidate the biological mechanisms of these diseases.

Acknowledgments: Supported in part by NIMH MN-42088 and MH-40524.

\section{REFERENCES}

Agren H, Lundqvist G (1984) Low levels of somatostatin in human CSF mark depressive episodes. Psychoneuroendocrinology 9:233-248.

American Psychiatric Association (1987) Diagnostic and Statistical Manual of Mental Disorders: Series, Third Edition-Revised. American Psychiatric Press, Washington, DC.

Amsterdam JD, Marinelli DL, Arger P, Winokur A (1987) Assessment of adrenal gland volume by computed tomography in depressed patients and healthy volunteers: A pilot study. Psychiatry Res 21:189-197.

Axelrod J, Reisine D (1984) Stress hormones: Their interaction and regulation. Science 224:452-459.

Banki CM, Bissette G, Arato M, O'Connor L, Nemeroff CB (1987) Cerebrospinal fluid corticotropin-releasing factor-like immunoreactivity in depression and schizophrenia. Am J Psychiatry 144:873-877.

Beal MF, Growdon JH, Mazurek MF (1986) CSF somatostatin-like immunoreactivity in dementia. Neurology 36:294-297.

Beisel WR, Cos JJ, Horton R, Cos JJ, Horton R, Chao PY, Forsham PH (1964) Physiology of urinary cortisol excretion. J Clin Endocrinol Metab 24:887-893.

Berger M, Doerr P, Lund R, Bronisch T, von Zerssen D (1982) Neuroendocrinological and neurophysiological studies in major depressive disorders: Are there biological markers for the endogenous subtype? Biol Psychiatry 17:1217-1242.

Berrettini WH, Nurnberger JI, Zerbe RL, Gold PW, Chrousos GP, Tomai T (1987) CSF neuropeptides in euthymic bipolar patients and controls. Br J Psychiatry 150:208-212.

Bissette G, Winderlov E, Walleus H, Karlsson I, Eklund K, Forsman A, Nemeroff CB (1986) Alterations in cerebrospinal fluid concentrations of somatostatin-like immunoreactivity in neuropsychiatric disorders. Arch Gen Psychiatry 43:1148-1151. 
Blazer D (1989) Medical intelligence, current concepts: Depression in the elderly. N Engl J Med 320:164-166.

Brown MR, Rivier C, Vale W (1984) Central nervous system regulation of adrenocorticotropin secretion: Role of somatostatins. Endocrinology 114:1546-1549.

Bunney WE, Hamburg DA (1963) Methods for reliable longitudinal observation of behavior. Arch Gen Psychiatry 9:280-284.

Carroll BJ (1985) Dexamethasone suppression test: A review of contemporary confusion. J Clin Psychiatry 46:13-24.

Carroll BJ, Mendels J (1976) Neuroendocrine regulation in affective disorders. In: Sacher EJ (Eds) Hormones, Behavior, and Psychopathology. Raven Press, New York, 193-224.

Cote GJ, Palmer WN, Leonhart K, Leong SS, Gagel RF (1986) The regulation of somatostatin production in human medullary thyroid carcinoma cells by dexamethasone. J Biol Chem 261:12930-12935.

Coyle JT, Price DL, DeLong MR (1983) Alzheimer's disease: A disorder of cortical cholinergic innervation. Science 219:1184-1190.

Davis KL, Davidson M, Yang RK, Davis BM, Siever LJ, Mohs RC, Ryan T, Coccaro E, Bierer L, Targum SD (1988) CSF somatostatin in Alzheimer's disease, depressed patients, and control subjects. Biol Psychiatry 24:710-712.

Doran AR, Rubinow DR, Roy A, Pickar D (1986) CSF somatostatin and abnormal response to dexamethasone administration in schizophrenic and depressed patients. Arch Gen Psychiatry 43:365-369.

Eddy RL, Jones AL, Gilliland PF, Ibarra JD, Thompson JQ, McMurry JF (1973) Cushing's syndrome: A prospective study of diagnostic methods. Am J Med 55:621-630.

Fischer P, Simanyi M, Danielczyk W (1990) Depression in dementia of the Alzheimer type and in multi-infarct dementia. Am J Psychiatry 147:1484-1487.

France RD, Urban B, Krishnan KRR (1988) CSF corticortrophin-releasing factor-like immunoreactivity in chronic pain patients with and without major depression. Biol Psychiatry 23:86-88.

Garcia-Sevilla JR, Magnusson T, Carlsson A (1978) Effect of intracerebroventricularly administered somatostatin on brain monoamine turnover. Brain Res 155:159-164.

Gold PW, Loriaux DL, Roy A, Kling MA, Calabrese JR, Kellner CH, Nieman LK, Post RM, Pickar D, Gallucci W, Avgerinos P, Paul S, Oldfield EH, Cutler GBJ, Chrousos PG (1986) Responses to corticotropin-releasing hormone in the hypercortisolism of depression and Cushing's disease. $\mathrm{N}$ Engl J Med 314:1329-1335.

Gothert M (1980) Somatostatin selectively inhibits NE release from hypothalamic neurons. Nature 288:86-88.

Greden JF, Flegel P, Haskett R, Dilsaver S, Carroll BJ, Grunhaus L, Genero N (1986) Age effects in serial hypothalamic-pituitary-adrenal monitoring. Psychoneuroendocrinology 11:195-204.

Greenwald BS, Mathe AA, Mohs RC, Levy MI, Johns CA, Davis KL (1986) Cortisol and Alzheimer's disease: II. Dexamethasone suppression, dementia severity, and affective symptoms. Am J Psychiatry 143:442-446.

Hamilton M (1960) A rating scale for depression. J Neurol Neurosurg Psychiatry 23:56-61.

Heisler S, Reisine T, Hook V, Axelrod J (1982) Somatostatin inhibits multireceptor stimulation of cyclic AMP formation and adrenocorticotropin secretion in mouse pituitary tumor cells. Proc Natl Acad Sci USA 79:6502-6507.

Hirano A, Zimmerman HM (1962) Alzheimer's neurofibrillary changes. Arch Neurol 7:73-88.

Holsboer F, Bardeleben U, Gerken A, Stalla G, Muller O (1984) Blunted corticotropin and normal cortisol responses to human corticotropin-releasing factor in depression. N Engl J Med 311:1127.

Hughes CP, Berg L, Danziger WL (1982) A new clinical scale for the staging of dementia. Br J Psychiatry 140:566-572.

Ishii T (1966) Distribution of Alzheimer's neurofibrillary changes in the brainstem and hypothalamus of senile dementia. Acta Neuropathol 6:181-187.

Katzman R (1986) Medical progress: Alzheimer's disease. N Engl J Med 314:964-972.

Kaye WH, Rubinow D, Gwirtsman HE, George DT, Jimerson DC, Gold PW (1988) CSF Somatostatin in anorexia nervosa and bulimia: Relationship to the hypothalamic-pituitary-adrenal cortical axis. Psychoneuroendocrinology 13:265-272.

Lamberts SWJ (1988) The role of somatostatin in the regulation of anterior pituitary hormone secretion and the use of its analogs in the treatment of human pituitary tumors. Endocr Rev 9:417-436. 
Lazarus LW, Newton N, Cohler B (1987) Frequency and presentation of depressive symptoms in patients with primary degenerative dementia. Am J Psychiatry 144:41-45.

Lesch KP, Ihl R, Frolich L, Rupprecht R, Muller U, Schulte HM, Maurer K (1990) Endocrine responses to growth hormone releasing hormone and corticotropin releasing hormone in early onset Alzheimer's disease. Psychiatry Res 33:107-112.

Lesch KP, Laux G, Schulte HM, Pfuller H, Beckmann H (1988) Corticotropin and cortisol response to human CRH as a probe for HPA system integrity in major depressive disorder. Psychiatry Res 24:25-34.

Lindholm J (1973) The renal excretion of cortisol. Scand J Clin Lab Invest 31:115-121.

Loosen PT (1985) The TRH-induced TSH response in psychiatric patients: A possible neuroendocrine marker. Psychoneuroendocrinology 10:237-260.

Lowy T, Reder AT, Gormley GJ, Meltzer HY (1988) Glucocorticoid sensitivity in depression: Relationship to the dexamethasone suppression test. Biol Psychiatry 24:619-630.

Maeda K, Tanimoto K, Terada T, Shintani T, Kakigi T (1991) Elevated urinary free cortisol in patients with dementia. Neurobiol Aging 12:161-163.

Maes M, Jacobs M-P, Suy E, Minner B, Raus J (1990) Prediction of the DST results in depressives by means of urinary-free cortisol excretion, dexamethasone levels, and age. Biol Psychiatry 28:349-357.

May C, Rapoport SI, Tomai TP, Chrousos GP, Gold PW (1987) CSF concentrations of CRH and corticotropin (ACTH) are reduced in patients with Alzheimer's disease. Neurology 37:535538.

McDonald WM, Nemeroff CB (1991) Neurotransmitters and neuropeptides in Alzheimer's disease. Psychiatry Clin North Am 14:421-442.

Molchan SE, Hill JL, Mellow AM, Lawlor BA, Martinez R, Sunderland T (1990) The dexamethasone suppression test in Alzheimer's disease and major depression: Relationship to dementia severity, depression, and CSF monoamines. Int Psychogeriatrics 2:99-122.

Molchan SE, Lawlor BA, Hill JL, Martinez RA, Davis CL, Mellow AM, Rubinow DR, Sunderland T (1991a) CSF Monoamine metabolites and somatostatin in Alzheimer's disease and major depression. Biol Psychiatry 29:1110-1118.

Molchan SE, Lawlor BA, Hill JL, Mellow AM, Davis CL, Martinez R, Sunderland T (1991b) The TRH stimulation test in Alzheimer's disease and major depression: Relationship to clinical and CSF measures. Biol Psychiatry 30:567-576.

Mouradian MM, Farah JM, Mohr E, Fabbrini G, O'Donohue TL, Chase TN (1986) Spinal fluid CRF reduction in Alzheimer's disease. Neuropeptides 8:393-400.

Nemeroff CB (1992) New vistas in neuropeptide research in neuropsychiatry: Focus on corticotropin-releasing factor. Neuropsychopharmacology 6:69-75.

Nemeroff CB, Krishna RR, Reed D, Leder R, Beam C, Dunnick NR (1992) Adrenal gland enlargement in major depression. Arch Gen Psychiatry 49:384-387.

Nemeroff CB, Widerlov E, Bissette G, Walleus H, Karlsson I, Eklund K, Kilts CD, Loosen PT, Vale W (1984) Elevated concentrations of CSF corticotropin-releasing factor-like immunoreactivity in depressed patients. Science 226:1342-1344.

Nicholson SA, Adrian TE, Gillham B, Jones MT, Bloom SR (1984) Effect of hypothalamic neuropeptides on corticotropin release from quarters of rat anterior pituitary gland in vitro. J Endocrinol 100:219-226.

Oram JJ, Edwardson J, Millard PH (1981) Investigation of cerebrospinal fluid neuropeptides in idiopathic senile dementia. Gerontology 27:216-223.

Patel Y, Rao K, Reichlin S (1977) Somatostatin in human cerebrospinal fluid. N Engl J Med 296:529-533.

Pomara N, Singh RR, Deptula D, LeWitt PA, Bissette G, Stanley M, Nemeroff CB (1989) CSF corticotropin-releasing factor (CRF) in $\mathrm{AD}$ : its relationship to severity of dementia and monoamine metabolites. Biol Psychiatry 26:500-504.

Raskind ME, Peskind E, Rivard MF, Veith R, Barnes R (1982) Dexamethasone suppression test and cortisol circadian rhythm in primary degenerative dementia. Am J Psychiatry 139:1468-1471.

Reisberg B, Ferris SH, DeLeon MJ, Crook T (1982) The global deterioration scale for assessment of primary degenerative dementia. Am J Psychiatry 139:1136-1139.

Reisine T (1984) Somatostatin inhibition of cyclic AMP accumulation and adrenocorticotropin release: Mechanisms of action and mode of self-regulation. Clin Neuropharmacol 7:56-57. 
Richardson UI, Schronbrunn A (1981) Inhibition of adrenocorticotropin secretion somatostatin in pituitary cells in culture. Endocrinology 108:281-284.

Rovner BW, Broadhead J, Spencer M (1989) Depression and Alzheimer's disease. Am J Psychiatry 146:350-353.

Rubin RT, Poland RE, Lesser IM, Winston RA, Blodgett ALN (1987) Neuroendocrine aspects of primary endogenous depression. Arch Gen Psychiatry 44:328-336.

Rubinow DR (1986) Cerebrospinal fluid somatostatin and psychiatric illness. Biol Psychiatry 21:341-365.

Rubinow DR, Post RM, Davis CL, Doran AR (1987) Somatostatin and GHRH: Mood and behavioral regulation. In: Nerozzi D, Goodwin FK, Costa E (Eds) Hypothalamic Dysfunction in Neuropsychiatric Disorders. Raven Press, New York, pp 137-152.

Saper CB, German DC (1987) Hypothalamic pathology in Alzheimer's disease. Neurosci Lett 74:364-370.

Sapolsky R, Armanini M, Packan D, Tombaugh G (1987) Stress and glucocorticoids in aging. Endocrinol Aging 16:965-980.

Serby M, Richardson SB, Rypma B, Twente S, Rotrosen JP (1986) Somatostatin regulation of the CRF-ACTH-cortisol axis. Biol Psychiatry 21:971-974.

Skare S, Pew B, Dysken M (1990) The dexamethasone suppression test in dementia: A review of the literature. J Geriatr Psychiatry Neurol 3:124-138.

Soininen HS, Jolkkonen JT, Teinikainen KJ (1984) Reduced cholinesterase activity and somatostatin-like immunoreactivity in the cerebrospinal fluid of patients with dementia of the Alzheimer type. J Neurol Sci 63:167-172.

Sparks DL, DeKosky ST, Markelsbery WR (1988) Alzheimer's disease: Aminergic-cholinergic alterations in hypothalamus. Arch Neurol 45:994-999.

Stokes PE, Stoll PM, Koslow SH, Maas JW, Swann A C., Robin SE (1984) Pretreatment DST and hypothalamic-pituitary-adrenocortical function in depressed patients and comparison groups, A multicenter study. Arch Gen Psychiatry 41:257-267.

Suemaru S, Hashimoto K, Ogasa T, Hirasawa R, Makino S, Ota Z, Kageyama J, Suemaru K (1991) Cerebrospinal fluid and plasma corticotropin-releasing hormone in senile dementia. Life Sci 48:1871-1879.

Sunderland T, Alterman IS, Yount D, Hill JL, Tariot PN, Newhouse PA, Mueller EA, Mellow AM, Cohen RM (1988a) A new scale for the assessment of depressed mood in dementia subjects. Am J Psychiatry 145:955-959.

Sunderland T, Hill JL, Lawlor BA, Molchan SE (1988b) NIMH Dementia Mood Assessment Scale (DMAS). Psychopharmacol Bull 24:747-753.

Sunderland T, Rubinow DR, Tariot PN, Cohen RM, Newhouse PA, Mellow AM, Mueller EA, Murphy DL (1987) CSF somatostatin in patients with Alzheimer's disease, older depressed patients, and age-matched control subjects. Am J Psychiatry 144:1313-1316.

Tamminga CA, Foster NL, Fedio P (1987) Alzheimer's disease: Low cerebral somatostatin levels correlate with impaired cognitive function and cortical metabolism. Neurology 37:161-165.

Vandewalle J, Charles G, Mardens Y, Mendelewicz J (1983) Dexamethasone suppression test in outpatients with primary affective disorder and health control subjects. Biol Psychiatry 18:385-389.

Wechsler, D (1987) Wechsler Memory Scale: Revised. Psychological Corp., Harcourt-BraceJovanovich, San Antonio, TX.

Wolkowitz OM, Rubinow DR, Breier A, Doran AR, Davis C, Pickar D (1987) Prednisone decreases CSF somatostatin in healthy humans: Implications for neuropsychiatric illness. Life Sci 41:1929-1933. 